\title{
Complete percutaneous decannulation from femoral venoarterial extracorporeal membrane oxygenation
}

Aakash Shah, MD, ${ }^{\mathrm{a}}$ Mehrdad Ghoreishi, MD, ${ }^{\mathrm{a}}$ Bradley S. Taylor, MD, ${ }^{\mathrm{a}}$ Shahab Toursavadkohi, MD, ${ }^{\mathrm{b}}$ and David J. Kaczorowski, MD, ${ }^{a}$ the University of Maryland Medical Center Extracorporeal Membrane Oxygenation (UMMC ECMO) Group*

\section{ABSTRACT}

Objectives: To evaluate the clinical outcomes and perioperative complications associated with complete percutaneous decannulation of femoral venoarterial extracorporeal membrane oxygenation (VA-ECMO) with the MANTA closure device.

Methods: This is a retrospective analysis of a single surgeon consecutive series of 14 patients at a single center who underwent decannulation from VA-ECMO, 10 of whom underwent a percutaneous method of femoral cannula removal.

Results: After a mean duration of VA-ECMO support of $7.4 \pm 3.8$ days, all 10 patients, with arterial cannulas ranging in size from 17 to $21 \mathrm{Fr}$, underwent percutaneous decannulation with the MANTA closure device, with immediate hemostasis. One patient had acute lower limb ischemia that was recognized intraoperatively and successfully treated with suction embolectomy. Two patients had a pseudoaneurysm at the distal perfusion catheter site recognized on perioperative imaging studies, one resolving with observation and the other necessitating thrombin injection. One patient had a hematoma that resolved with observation.

Conclusions: Percutaneous decannulation from VA-ECMO using the MANTA largebore vascular closure device is feasible and results in immediate hemostasis with excellent angiographic results. (JTCVS Techniques 2021;6:75-81)

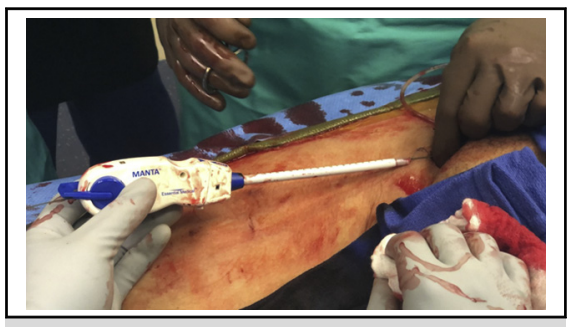

MANTA closure device deployed for percutaneous closure of a femoral arterial cannulation site.

\section{CENTRAL MESSAGE}

Use of the MANTA large-bore vascular closure device allows for complete percutaneous decannulation of femoral VA-ECMO.

\section{PERSPECTIVE}

Femoral VA-ECMO is frequently initiated percutaneously, but removal of the arterial cannula generally requires incision and exposure of the femoral artery. Current methods for percutaneous closure of this site generally require a preclosure technique. The MANTA vascular closure device offers a percutaneous closure method with a high rate of immediate hemostasis, without the need for preclosure.

See Commentaries on pages 82 and 84 .
From the Divisions of ${ }^{\mathrm{a}}$ Cardiac Surgery and ${ }^{\mathrm{b}}$ Vascular Surgery, Department of Surgery, University of Maryland School of Medicine, Baltimore, Md.

* UMMC ECMO Group members: Chetan Pasrija, MD, ${ }^{\mathrm{a}}$ Douglas Tran, MD, ${ }^{\mathrm{a}}$ Mohamed Abdullah MD, PhD, ${ }^{a}$ Ronson J. Madathil, MD, ${ }^{a}$ Kristopher B. Deatrick, MD, ${ }^{a}$ Michael A. Mazzeffi, MD, ${ }^{\mathrm{c}}$ Ashley Menne, MD, ${ }^{\mathrm{c}}$ Jay Menaker, MD, ${ }^{\mathrm{c}}$ James S. Gammie, MD, ${ }^{\mathrm{a}}$ and Bartley P. Griffith, $\mathrm{MD}^{\mathrm{a}}$

Received for publication Sept 25, 2020; accepted for publication Nov 12, 2020; available ahead of print Nov 21, 2020.

Address for reprints: David J. Kaczorowski, MD, Division of Cardiac Surgery, Department of Surgery, University of Maryland School of Medicine, 110 S Paca St, 7th Floor, Baltimore, MD 21201 (E-mail: Dkaczorowski@som.umaryland. edu).

2666-2507

Copyright $\odot 2020$ The Authors. Published by Elsevier Inc. on behalf of The American Association for Thoracic Surgery. This is an open access article under the CC BY-NCND license (http://creativecommons.org/licenses/by-nc-nd/4.0/).

https://doi.org/10.1016/j.xjtc.2020.11.005 $\downarrow$ Video clip is available online.

Venoarterial extracorporeal membrane oxygenation (VA-ECMO) is commonly initiated via cannulas placed in the common femoral artery and common femoral vein. Cannulation can be performed using an open technique; however, percutaneous access with ultrasound guidance can be performed rapidly at the bedside and has become the preferred method at many centers. ${ }^{1}$ Removal of the arterial cannula generally requires an incision, with exposure and repair of the femoral artery. This not only necessitates transportation to the operating room and 


$$
\begin{aligned}
& \text { Abbreviations and Acronyms } \\
& \text { CT }=\text { computed tomography } \\
& \text { ECMO }=\text { extracorporeal membrane oxygenation } \\
& \text { SFA }=\text { superficial femoral artery } \\
& \text { VA }=\text { venoarterial }
\end{aligned}
$$

induction of general anesthesia, but also exposes the patient to the morbidity of a groin incision and the risk of wound infection and lymphatic leak. Several centers have reported the use of percutaneous closure of arterial cannulation sites using suture closure systems, such as the Perclose ProGlide (Abbott Vascular, Santa Clara, Calif). ${ }^{2-4}$ However, these systems generally require additional time to preclose the site before cannula insertion, which might not be ideal for rapidly declining patients. Furthermore, sutures from the closure system may be exposed to the environment in the period between insertion and decannulation, which could increase the risk of infection.

In our center, we previously tested a large-bore vascular closure system, the MANTA vascular closure device (Teleflex, Morrisville, NC), in a large animal preclinical model and were able to successfully close ECMO arterial cannulation sites. ${ }^{5}$ This device uses a bioresorbable anchor and collagen plug to close the arteriotomy. We hypothesized that we could use the MANTA to successfully close arterial ECMO cannulation sites in patients supported with VA-ECMO, with the additional use of a percutaneous closure device for removal of a distal perfusion catheter in the superficial femoral artery (SFA), which are placed routinely at the time of cannulation at our center.

\section{METHODS}

\section{Study Design and Patients}

This was a retrospective observational study of patients who received peripheral VA-ECMO between January and May 2020, performed with Institutional Review Board approval (HP-00088089). The study included consecutive patients who underwent percutaneous removal of their arterial ECMO cannula with the MANTA along with removal of distal perfusion catheters and closure of the SFA with an Angio-Seal VIP (Terumo Interventional Systems, Somerset, NJ) or MYNX (Cardinal Health, Dublin, Ohio) vascular closure device. The MANTA device was the preferred method for ECMO decannulation in all patients who were placed on femoral VAECMO percutaneously. Patients were excluded from use of the MANTA and underwent traditional closure if their initial ECMO cannulation strategy used an incision to cannulate target vessels $(n=1)$, if central cannulation $(n=1)$ or axillary cannulation $(n=1)$ was used, or if there was significant tissue breakdown at the femoral cannulation site $(\mathrm{n}=1)$. Ten of 14 consecutive patients underwent percutaneous arterial cannula removal and closure with the MANTA device by a single surgeon.

\section{Surgical Technique}

All procedures were performed in the operating room under general anesthesia with a multidisciplinary team, including cardiac and vascular surgery. All patients, with the exception of 1 patient in whom VA-ECMO was used for intraoperative support, underwent a computed

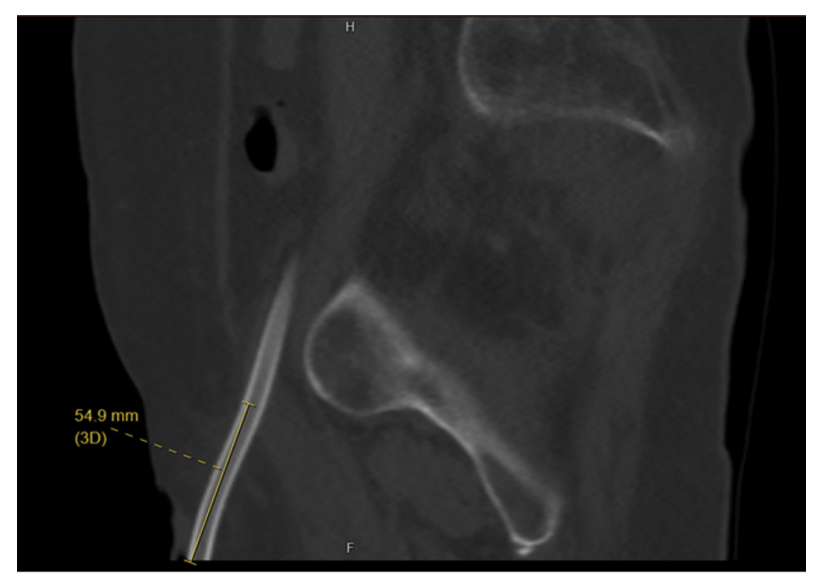

FIGURE 1. Computed tomography $(C T)$ scan of the abdomen and pelvis without contrast in a patient with extracorporeal membrane oxygenation $(E C M O)$ cannulas in place before decannulation. The depth of the arterial cannula from skin to the femoral artery entry site is measured in the sagittal plane.

tomography (CT) scan of the abdomen and pelvis without contrast while cannulas were in place before the removal of ECMO catheters, to measure the depth of the arterial cannula from the skin to the femoral artery (Figure 1). Depth was measured in the sagittal plane, and $1 \mathrm{~cm}$ was added to this measurement to determine the depth of MANTA deployment. For the patient who received VA-ECMO for intraoperative support only, this depth was measured using the included preinsertion measuring device according to the manufacturer's instructions. Early in our experience, contralateral femoral arterial access was obtained in the event that hemostasis was not successful or an acute arterial occlusion occurred necessitating intervention.

On weaning the patient from ECMO, a \#1 Prolene purse-string suture was placed in the skin around the venous cannula insertion site and tied down on removal of the venous cannula. The arterial cannula was clamped and cut from the circuit. The distal perfusion catheter was disconnected from the arterial cannula and connected to arterial line pressure tubing to monitor distal pressure. Proximal to the clamp, the arterial cannula was directly accessed with an 18-gauge needle through which an 0.035 -inch J-tip guidewire was inserted. The arterial cannula was then removed over the wire, and manual pressure was applied at the insertion site. The MANTA sheath was then inserted over the wire and pulled back to the deployment level (predetermined to be at least $1 \mathrm{~cm}$ farther than the

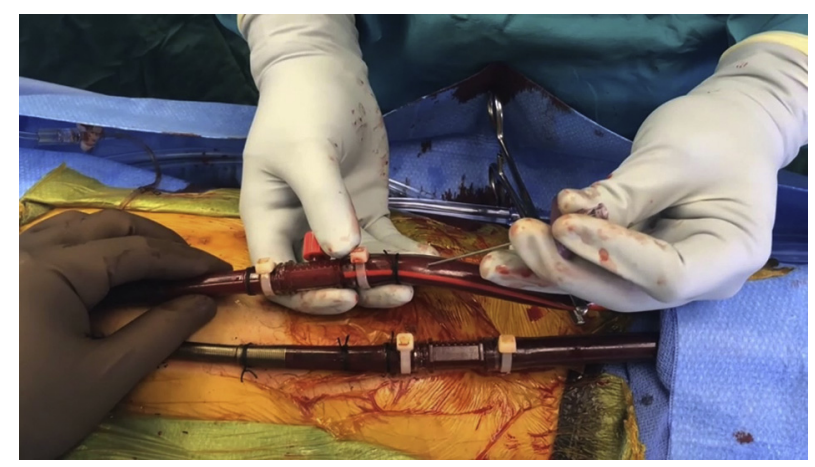

VIDEO 1. Complete percutaneous decannulation from femoral venoarterial extracorporeal membrane oxygenation and technique for deployment of the MANTA device at the arterial cannulation site. Video available at: https://www.jtcvs.org/article/S2666-2507(20)30644-1/fulltext. 
TABLE 1. Patient Demographics and Comorbidities

\begin{tabular}{|c|c|c|c|c|c|c|c|c|c|c|c|}
\hline \multirow[b]{2}{*}{ Patient } & \multirow[b]{2}{*}{ Age, $y$} & \multirow[b]{2}{*}{ Male sex } & \multirow[b]{2}{*}{ BMI, $\mathrm{kg} / \mathrm{m}^{2}$} & \multicolumn{8}{|c|}{ Preexisting comorbidities } \\
\hline & & & & Hypertension & DM & CAD & HLD & Heart failure & PVD & Smoker & $\overline{\text { CKD }}$ \\
\hline 1 & 54 & Yes & 31.0 & No & No & No & No & No & No & Yes & No \\
\hline 2 & 57 & Yes & 29.8 & Yes & No & Yes & Yes & Yes & No & Yes & No \\
\hline 3 & 74 & No & 32.6 & Yes & Yes & Yes & Yes & No & Yes & No & No \\
\hline 4 & 46 & Yes & 42.6 & Yes & No & Yes & Yes & Yes & No & No & Yes \\
\hline 5 & 67 & Yes & 32.5 & Yes & No & No & Yes & No & No & Yes & No \\
\hline 6 & 63 & No & 53.1 & Yes & Yes & No & Yes & No & No & No & No \\
\hline 7 & 63 & Yes & 35.6 & Yes & No & Yes & Yes & No & Yes & No & Yes \\
\hline 8 & 66 & Yes & 32.8 & Yes & Yes & Yes & Yes & No & No & No & No \\
\hline 9 & 64 & Yes & 24.6 & No & No & Yes & No & No & No & No & No \\
\hline 10 & 61 & No & 29.4 & Yes & Yes & No & Yes & No & No & No & No \\
\hline Total, $\mathrm{n}(\%) /$ mean $\pm \mathrm{SD}$ & $61.5 \pm 7.7$ & $7(70)$ & $35.0 \pm 8.3$ & $8(80)$ & $4(40)$ & $6(60)$ & $8(80)$ & $2(20)$ & $2(20)$ & $3(30)$ & $2(20)$ \\
\hline
\end{tabular}

$B M I$, Body mass index; $D M$, diabetes mellitus; $C A D$, coronary artery disease; $H L D$, hyperlipidemia; $P V D$, peripheral vascular disease; $C K D$, chronic kidney disease.

measured depth of the arterial cannula). The MANTA was then deployed, as has been described previously ${ }^{5}$ (Video 1). Distal flow was confirmed by arterial pressure in the distal perfusion catheter and palpation or Doppler detection of distal extremity pulses. If flow was satisfactory, the distal perfusion catheter was removed using either an Angio-Seal or MYNX closure device or with manual pressure, at the surgeon's discretion.

\section{Outcomes}

Primary outcomes were device failure, immediate hemostasis, and acute lower limb ischemia. Secondary outcomes were perioperative complications detected by either routine CT angiography, angiography, or arterial duplex, including arterial thrombus, arterial dissection, pseudoaneurysm, arterial stenosis $(>50 \%)$, arteriovenous fistula, and hematoma or clinical assessment, including groin infection and lymphocele. Survival to discharge was also reported.

\section{Statistical Analysis}

Continuous variables are reported as mean \pm standard deviation. Categorical variables are presented as number and percentage. All data analysis was performed using R version 3.4.0 (R Foundation for Statistical Computing, Vienna, Austria).

\section{RESULTS}

\section{Patient Characteristics}

Between January and May 2020, 14 consecutive patients underwent decannulation, 10 of whom underwent percutaneous removal of VA-ECMO arterial cannulas and were analyzed. Baseline patient demographic data are reported in Table 1. Of note, the average body mass index for these patients was $35.0 \mathrm{~kg} / \mathrm{m}^{2}$, and the majority had multiple medical comorbidities.

Of the 10 patients, 1 patient was placed on VA-ECMO for procedural support for removal of a large posterior mediastinal mass compressing the left atrium, and 1 patient was placed on VA-ECMO for calcium-channel blocker overdose. The remaining 8 patients were placed on VA-ECMO for cardiogenic shock $(\mathrm{n}=4)$, for massive pulmonary embolism $(n=2)$, or as a bridge to a left ventricular assist device $(\mathrm{n}=2)$. The mean duration of support was $7.4 \pm 3.8$ days (Table 2).

TABLE 2. ECMO Characteristics

\begin{tabular}{|c|c|c|c|c|c|c|c|c|}
\hline Patient & $\begin{array}{l}\text { Indication } \\
\text { for support }\end{array}$ & $\begin{array}{c}\text { ECMO } \\
\text { duration, } \\
\text { d }\end{array}$ & $\begin{array}{c}\text { CFA } \\
\text { diameter, } \\
\text { mm }\end{array}$ & $\begin{array}{c}\text { Arterial } \\
\text { cannula, } \\
\text { Fr }\end{array}$ & $\begin{array}{c}\text { Cannula } \\
\text { depth, } \\
\text { cm }\end{array}$ & $\begin{array}{c}\text { SFA } \\
\text { diameter, } \\
\text { mm }\end{array}$ & $\begin{array}{c}\text { Distal } \\
\text { perfusion } \\
\text { catheter, Fr }\end{array}$ & $\begin{array}{c}\text { Ipsilatera } \\
\text { venous } \\
\text { cannula }\end{array}$ \\
\hline 1 & Ca channel overdose & 5 & 12.0 & 21 & 5.5 & 9 & 6 & No \\
\hline 2 & Bridge to LVAD & 12 & 10.0 & 19 & 5.5 & 7.5 & 6 & No \\
\hline 3 & Cardiogenic shock & 4 & 7.0 & 17 & 6.5 & 6.3 & 6 & No \\
\hline 4 & Bridge to LVAD & 8 & 13.0 & 21 & 6.0 & 8.7 & 6 & Yes \\
\hline 5 & Massive PE & 6 & 12.3 & 19 & 4.0 & 8.9 & 6 & Yes \\
\hline 6 & Procedural support & 0.5 & - & 17 & - & - & 6 & Yes \\
\hline 7 & Cardiogenic shock & 7 & 10.3 & 19 & 6.5 & 7.1 & 6 & Yes \\
\hline 8 & Cardiogenic shock & 11 & 9.8 & 19 & 6.0 & 7.0 & 6 & Yes \\
\hline 9 & Cardiogenic shock & 13 & 10.3 & 17 & 6.3 & 8.1 & 6 & Yes \\
\hline 10 & Massive PE & 7 & 10.2 & 19 & 5.5 & 7.3 & 6 & No \\
\hline Total, mean $\pm \mathrm{SD} / \mathrm{n}(\%)$ & - & $7.4 \pm 3.8$ & $10.5 \pm 1.8$ & - & $5.8 \pm 0.8$ & $7.8 \pm 1.0$ & - & $6(60 \%)$ \\
\hline
\end{tabular}

ECMO, Extracorporeal membrane oxygenation; $C F A$, common femoral artery; SFA, superficial femoral artery; $L V A D$, left ventricular assist device; $P E$, pulmonary embolism. 
TABLE 3. Outcomes and complications

\begin{tabular}{|c|c|c|c|c|c|c|c|}
\hline Patient & $\begin{array}{l}\text { MANTA } \\
\text { size, Fr }\end{array}$ & $\begin{array}{l}\text { Distal perfusion } \\
\text { closure }\end{array}$ & $\begin{array}{l}\text { Postoperative } \\
\text { imaging }\end{array}$ & $\begin{array}{l}\text { Stenosis at } \\
\text { closure site }\end{array}$ & $\begin{array}{l}\text { Immediate } \\
\text { hemostasis }\end{array}$ & $\begin{array}{l}\text { Perioperative } \\
\text { complications }\end{array}$ & $\begin{array}{l}\text { Survival to } \\
\text { discharge }\end{array}$ \\
\hline 1 & 18 & Angioseal $6 \mathrm{Fr}$ & Angiogram & No & Yes & None & Yes \\
\hline 2 & 18 & MYNX 6/7 Fr & CTA & No & Yes & Hematoma & Yes \\
\hline 3 & 18 & MYNX 6/7 Fr & Angiogram, duplex & No & Yes & $\begin{array}{l}\text { Acute lower limb ischemia, } \\
\text { pseudoaneurysm at SFA }\end{array}$ & Yes \\
\hline 4 & 18 & Angioseal $6 \mathrm{Fr}$ & Duplex & No & Yes & None & Yes \\
\hline 5 & 18 & Manual pressure & Angiogram, CTA, duplex & No & Yes & None & Yes \\
\hline 6 & 18 & Angioseal $6 \mathrm{Fr}$ & Duplex & No & Yes & None & No \\
\hline 7 & 18 & Angioseal $6 \mathrm{Fr}$ & Duplex & No & Yes & None & Yes \\
\hline 8 & 18 & Angioseal $6 \mathrm{Fr}$ & CTA, duplex & No & Yes & None & Yes \\
\hline 9 & 18 & Angioseal $6 \mathrm{Fr}$ & Duplex & No & Yes & None & Yes \\
\hline 10 & 18 & MYNX 6/7 Fr & Duplex & No & Yes & Psuedoaneurysm at SFA & Yes \\
\hline Total, n (\%) & - & - & - & $0(0 \%)$ & $10(100 \%)$ & - & $9(90 \%)$ \\
\hline
\end{tabular}

CTA, Computed tomography angiography, SFA, superficial femoral artery.

The arterial cannula size varied from 17 to $21 \mathrm{Fr}$. The mean arterial cannula depth from the skin to the femoral artery was $5.8 \pm 0.8 \mathrm{~cm}$ as measured on CT scan. CT scan was not performed for the patient who was on VA-ECMO support for an operative procedure. Six patients $(60 \%)$ had an ipsilateral venous cannula. All patients had a distal perfusion catheter placed in the SFA, in accordance with our standard practice (Table 2).

\section{Outcomes}

An 18-Fr MANTA device was used for arterial cannula site closure in all patients. For the distal perfusion site, closure was performed with a 6/7-Fr MYNX device in 3 patients, with a 6-Fr Angio-Seal device in 6 patients, and with manual pressure in 1 patient (Table 3 ).

No patient experienced device failure, and all patients had immediate hemostasis at the arterial cannula site after MANTA closure. Early in our experience, angiography was performed to confirm adequate site closure and patency of the target vessel. Excellent angiographic hemostasis was observed without extravasation of contrast or obstruction of the vessel (Figure 2). Another patient underwent a CT angiography, and the closure site was incidentally imaged (Figure 3). Excellent closure of the site without extravasation or obstruction was observed.

Acute lower limb ischemia after closure, recognized intraoperatively by the absence of arterial duplex signals, occurred in 1 patient. A subsequent confirmatory angiography was performed, and suction embolectomy from contralateral arterial access returned blood flow to the lower extremity (Table 3, Figure 4).

After percutaneous arterial decannulation and arterial closure using the MANTA vascular closure device, 2 patients were found to have a pseudoaneurysm at the superficial

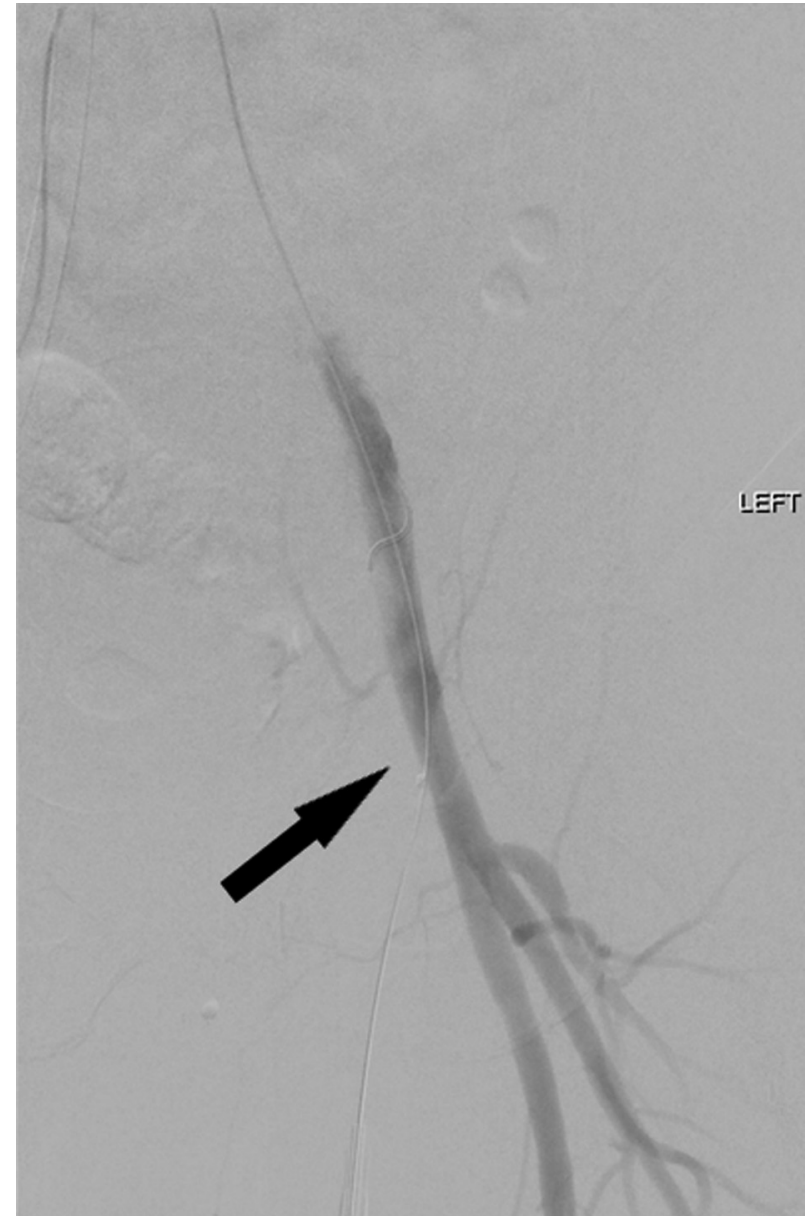

FIGURE 2. Post-decannulation angiogram after percutaneous removal of an arterial extracorporeal membrane oxygenation (ECMO) cannula and closure with the MANTA vascular closure device, demonstrating an excellent result without extravasation of contrast or obstruction of the vessel. An arrow indicates the location of the MANTA device. 


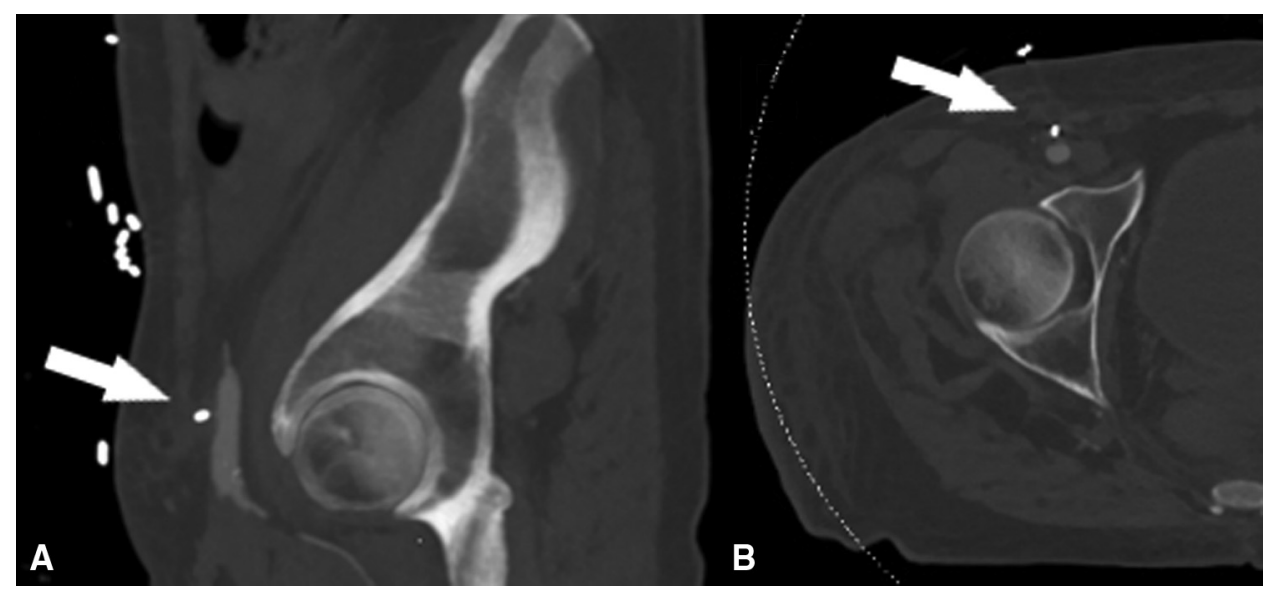

FIGURE 3. Post-decannulation A, sagittal and B, coronal computed tomography angiography images of MANTA closure site of the common femoral artery after percutaneous arterial extracorporeal membrane oxygenation $(E C M O)$ cannula removal. The images illustrate satisfactory vessel closure without extravasation or obstruction of arterial flow. An arrow indicates the location of the MANTA device in each image.

femoral arterial site. One patient was managed conservatively, and the other required thrombin injection. An additional patient had a hematoma, which was managed conservatively and did not require intervention. At the time of this report, 1 patient had not yet undergone imaging assessment of the closure site. Of the 10 patients in the study, 9 survived to discharge, and 1 died after VA-ECMO decannulation but before hospital discharge (Table 3).

\section{DISCUSSION}

Although removal of the arterial ECMO cannula generally requires an incision with exposure and repair of the femoral artery, several methods of percutaneous closure have been reported. Each method has potential pitfalls, however. The use of percutaneous suture closure systems generally requires placement before dilation of the blood vessel, and the sutures may be exposed to the environment while the patient is supported on ECMO. Some centers simply pull percutaneously deployed arterial and distal perfusion cannulas and hold manual pressure. Previously, we have pulled and held pressure at distal perfusion sites with acceptable results; however, we generally use arterial cannulae ranging from 17 to $21 \mathrm{Fr}$ and have been reluctant to pull and hold pressure at the arterial cannulation sites owing to concerns about potential complications, including hematoma, pseudoaneurysm, and lack of immediate hemostasis, particularly in patients who require ongoing anticoagulation or have coagulopathy.

The MANTA large-bore vascular closure device has been successfully used for closure of large-bore vascular access in the setting of transcatheter aortic valve replacement, thoracic endovascular stent grafting, and endovascular stenting. ${ }^{6-12}$ It has been demonstrated to yield rapid hemostasis with a high rate of technical success and a low rate of complications. We have previously shown excellent radiographic results after using the MANTA device to close arterial cannulation sites in a large animal model. ${ }^{5}$ Case reports of successful use of the MANTA device in isolated cases of VA-ECMO decannulation have been reported recently. ${ }^{13-15}$ Here we report the use of the MANTA device in 10 consecutive patients eligible for percutaneous decannulation.

To correctly deploy the MANTA device, the depth of insertion must be accurately measured. A depth locator is provided with the device to measure the depth of the access site if the cannula or sheath used to access the artery is removed at the same setting. However, if the depth is not measured at the time of arterial access, or if there is change in the tissue depth due to edema or hematoma, then the depth of the arterial access site must be reassessed. CT scans before decannulation were used to ensure that the depth measurements were as accurate as possible. CT scans generally require transport of the patient on ECMO. Some centers may not have adequate personnel for transport during ECMO, and patients may be hemodynamically unstable. Ultrasound may be an acceptable alternative ${ }^{14}$ that can be performed at the bedside. In addition to mitigating the need for patient transport, ultrasound also has the advantage of lower cost.

In this series, we observed a $100 \%$ rate of technical success, with immediate hemostasis in all patients at the arterial cannulation site. In patients with small vessels or those in whom a large arterial cannula is used, there is potential for thrombus formation between the insertion site of the arterial cannula in the common femoral artery and the SFA cannulation site. One patient in this series developed thromboembolism of the SFA, presumably from thrombus formation between the arterial cannula and the distal perfusion catheter, which was successfully treated percutaneously at the time of decannulation with suction 


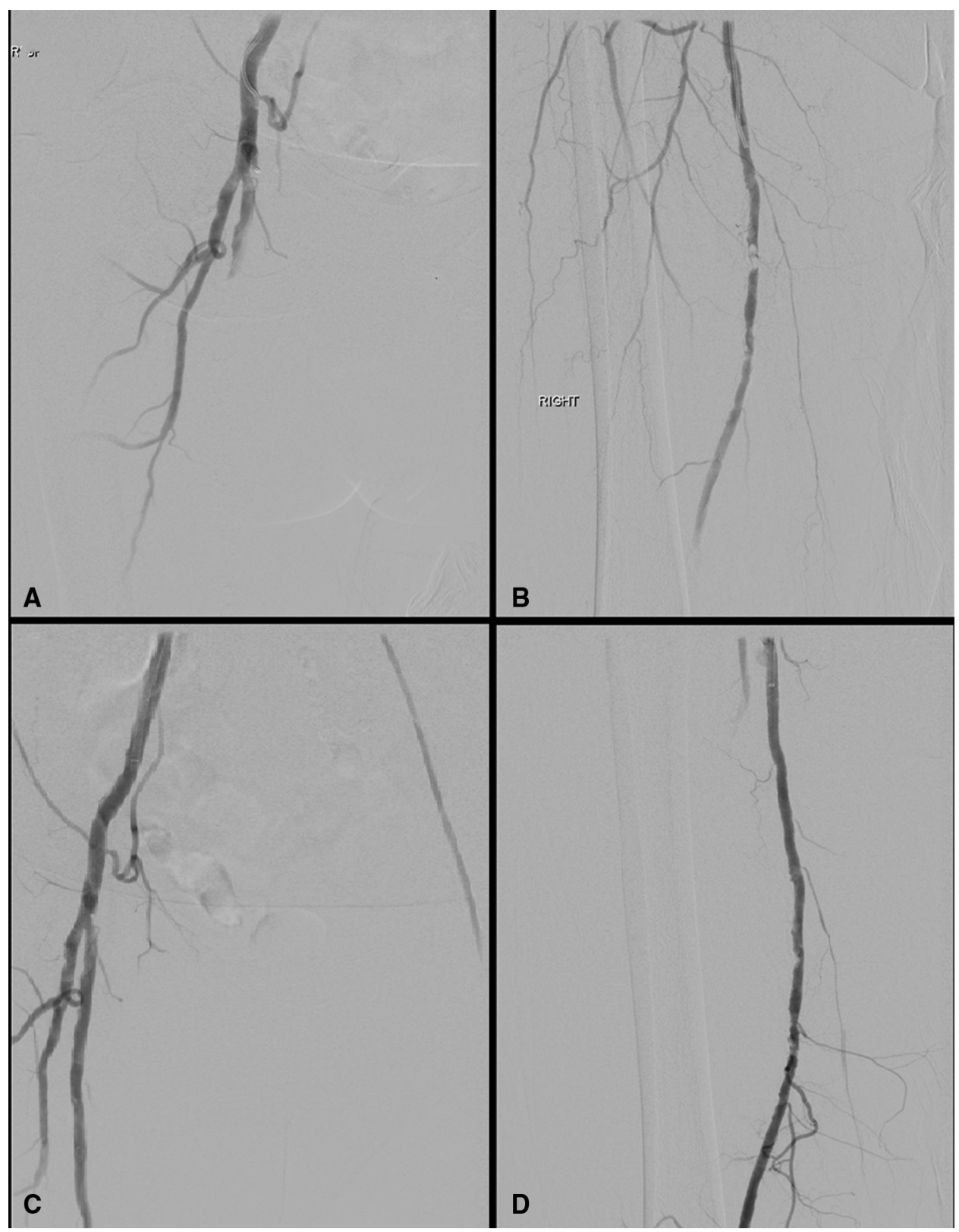

FIGURE 4. Post-decannulation angiograms in a patient with percutaneously treated embolic disease in a diseased femoral system at the time of percutaneous extracorporeal membrane oxygenation (ECMO) cannula removal. A, Confirmatory angiography demonstrating poor flow distal to the decannulation site. B, Selective angiography demonstrating acute embolus in the superficial femoral artery (SFA). C, Angiography after suction embolectomy demonstrating return of blood flow to the lower extremity. D, Diffuse disease is noted throughout the femoral vasculature.

embolectomy. This case illustrates the importance of a team with members who have advanced endovascular skills.

The 2 post-decannulation pseudoaneurysms were identified at the distal perfusion catheter insertion site in the SFA. A closure device was not used in 1 patient, owing to the presence of acute arterial occlusion and diffuse arterial disease noted on angiography. The other patient experienced failure of the MYNX device, and manual pressure was held thereafter. Both of these cases suggest the value of a vascular closure device for the distal perfusion catheter site when the patient anatomy is suitable.

Broader experience with larger cohorts of patients will be needed to more comprehensively assess the applicability of this procedure, its success rate, and associated complications. The main advantage of using this technique is the avoidance of a groin incision, which may be susceptible to infection, poor healing, and lymph leak. We would not currently recommend this strategy of decannulation in 
patients who have undergone a method of cannulation other than percutaneous femoral, such as central or axillary cannulation, or have known or suspected intra-arterial thrombus. The cost associated with the device is the major drawback of the procedure. This may be offset by shorter operative times and reduced incisional complication rates. Ultimately, as experience is gained with this technique, it may be possible to perform arterial ECMO decannulation at the bedside without the use of general anesthesia.

\section{Conflict of Interest Statement}

Dr Kaczorowski has a patent for devices for endovascular access through extracorporeal life support circuits. All other authors reported no conflicts of interest.

The Journal policy requires editors and reviewers to disclose conflicts of interest and to decline handling or reviewing manuscripts for which they may have a conflict of interest. The editors and reviewers of this article have no conflicts of interest.

\section{References}

1. Squiers JJ, Lima B, DiMaio JM. Contemporary extracorporeal membrane oxygenation therapy in adults: fundamental principles and systematic review of the evidence. J Thorac Cardiovasc Surg. 2016;152:20-32.

2. Xu X, Liu Z, Han P, He M, Xu Y, Yin L, et al. Feasibility and safety of total percutaneous closure of femoral arterial access sites after veno-arterial extracorporeal membrane oxygenation. Medicine (Baltimore). 2019;98:e17910.

3. Hwang JW, Yang JH, Sung K, Song YB, Hahn JY, Choi JH, et al. Percutaneous removal using Perclose ProGlide closure devices versus surgical removal for weaning after percutaneous cannulation for venoarterial extracorporeal membrane oxygenation. J Vasc Surg. 2016;63:998-1003.e1.

4. Majunke N, Mangner N, Linke A, Boudriot E, Erbs S, Tietz F, et al. Comparison of percutaneous closure versus surgical femoral cutdown for decannulation of large-sized arterial and venous access sites in adults after successful weaning of veno-arterial extracorporeal membrane oxygenation. J Invasive Cardiol. 2016;28:415-9.

5. Pasrija C, Bernstein DA, Rice M, Tran D, Morales D, Grintz T, et al. Sutureless closure of arterial cannulation sites. Innovations (Phila). 2020;15: $138-41$.

6. Van Mieghem NM, Latib A, van der Heyden J, van Gils L, Daemen J, Sorzano T, et al. Percutaneous plug-based arteriotomy closure device for large-bore access: a multicenter prospective study. JACC Cardiovasc Interv. 2017;10:613-9.

7. De Palma R, Settergren M, Rück A, Linder R, Saleh N. Impact of percutaneous femoral arteriotomy closure using the MANTA $^{\mathrm{TM}}$ device on vascular and bleeding complications after transcatheter aortic valve replacement. Catheter Cardiovasc Interv. 2018;92:954-61.

8. Biancari F, Romppanen H, Savontaus M, Siljander A, Mäkikallio T, Piira OP, et al. MANTA versus ProGlide vascular closure devices in transfemoral transcatheter aortic valve implantation. Int J Cardiol. 2018;263:29-31.

9. Moriyama N, Lindström L, Laine M. Propensity-matched comparison of vascular closure devices after transcatheter aortic valve replacement using MANTA versus ProGlide. EuroIntervention. 2019;14:e1558-65.

10. Gheorghe L, Brouwer J, Mathijssen H, Nijenhuis VJ, Rensing BJ, Swaans MJ, et al. Early outcomes after percutaneous closure of access site in transfemoral transcatheter valve implantation using the novel vascular closure device collagen plug-based MANTA. Am J Cardiol. 2019;124:1265-71.

11. Wood DA, Krajcer Z, Sathananthan J, Strickman N, Metzger C, Fearon W, et al Pivotal clinical study to evaluate the safety and effectiveness of the MANTA percutaneous vascular closure device. Circ Cardiovasc Interv. 2019; 12:e007258.

12. Moccetti F, Brinkert M, Seelos R, Ockert S, Bossard M, Cuculi F, et al. Insights from a multidisciplinary introduction of the MANTA vascular closure device. JACC Cardiovasc Interv. 2019;12:1730-6.

13. Hassan MF, Lawrence M, Lee D, Velazco J, Martin C, Reddy R. Simplified percutaneous VA ECMO decannulation using the MANTA vascular closure device: initial US experience. J Card Surg. 2020;35:217-21.

14. Dahlbacka S, Vähäsilta T, Moriyama N, Vainikka T, Aho P, Laine M. Ultrasoundnavigated MANTA deployment after removal of extracorporeal membrane oxygenation cannula. Ann Thorac Surg. 2020;110:e307-9.

15. Montero-Cabezas JM, van der Meer RW, van der Kley F, Elzo Kraemer CV, López Matta JE, Schalij MJ, et al. Percutaneous decannulation of femoral venoarterial ECMO cannulas using MANTA vascular closure device. Can J Cardiol. 2019;35:796.e9-11.

Key Words: mechanical circulatory support, extracorporeal membrane oxygenation, percutaneous vascular closure 